\title{
RIVER SAND AS AN ALTERNATIVE TO TOP SOIL FOR RAISING COCONUT SEEDLINGS IN POLYBAGS
}

\author{
R. R. A. PERIES and J.M.D. T. EVERARD
}

Coconut Research Institute of Sri Lanka.

\section{ABSTRACT}

Different combinations of river sand, cow dung and coir dust were compared with the conventional polybag mixtures to study whether seed germination would be affected by the substitution of top soil with river sand.

The seed nut germination at 20 weeks was significantly reduced in the sand substituted media, but the difference disappered by 24 weeks from laying. The lower rate of germination was also associated with a reduction of seedling vigour at 30 weeks, probably due to poor seedling nutrition.

River sand could be used as an alternative to top soil. provided the nutritive status of the sand is improved and refinements are made to decrease its rate of drying.

\section{INTRODUCTION}

Coconut seedlings are raised in a nursery prior to field planting as proper care and maintenance of a seed bed facilitates the selection of early germinating vigorous seedlings. Seedling vigour is correlated with adult palm characters such as early flowering and high nut and copra yield (Liyanage, 1957). In a conventional nursery, seed nuts are laid in nursery beds spaced at $45 \mathrm{~cm}$ between row and $15 \mathrm{~cm}$ within row and remain there for about $7-9$ months until seedlings are selected for field planting (Anonymous, 1971). Raising of coconut seedlings in polybags was introduced in 1969 (Wuident, 1981), and is now popular in major coconut growing countries including Sri Lanka.

Polybag nursery is preferred to the conventional field nursery since intensive care and management of individual seedlings result in vigorous seedlings which attain rapid reproductive development. It also minimizes the shock at field planting in the absence of damage to roots (Wuidart, 1981). The polybag also facilitates prolonging the nursery period until the environment is conducive for field planting although no particular advantage has been obtained by planting older seedlings (Ho et. al., 1978).

The polybag usually takes in about $16-18 \mathrm{~kg}$ of top soil (Wuidart, 1981). Currently Sri Lanka requires to raise about 2 million seedlings per year (Liyanage, 1982) and this could amount to a top soil requirement of over $35,000 \mathrm{t}$. Unless seedlings are raised in close proximity to the planting sites the cost of transport will also increase. This and the extra labour and material costs are considered the major constraints in the polybag nursery system. Continuous removal of top soil from the nursery site would also require the shifting of the site periodically. 
On coastal clays, top soil mixed with sand in the ratio of $3: 1$ is a satisfactory mixture for the polybags (Ho et. al., 1977). Workers in the Philippines (Cano et. al., 1981) have recommended the use of loose friable soil for potting coconut seedlings. The current practice in Sri Lanka is a 1:2:3 mixture of top soil, cow dung and coir dust. The mixture used earlier contained more top soil (3:2:1). These mixtures have all proved to be successful in practice, yet the requirement of humiferous top soil could be large. It was therefore, felt necessary to investigate possible options to replace humiferous top soil in the polybag potting mixture with particular interest in the use of river sand found abundantly in close proximity to most coconut nurseries. If germination and early

Research Institute, Sri Lanka from June 1990 to February 1991. The site is located in the intermediate zone of north-western Sri Lanka. The average day temperature at the site was around $30^{\circ} \mathrm{C}$ and the average recorded pan evaporation was $4 \mathrm{~mm}$ per day. The rainfall at the site during the period of study was uneven with dry spells occurring in mid July to early October and from January onward (Table 1).

Table 1 The intensity and distribution of rainfall during the period, June, 1990 - February 1991 at the Bandirippuwa Research Nursery

\begin{tabular}{llcc}
\hline Year/Month & Rainfall (mm) & Rainy days \\
\hline 1990 June & 20.9 & 5 \\
July & 156.3 & 13 \\
Aug & 0.3 & 1 \\
Sep & 11.9 & 8 \\
Oct & 395.1 & 23 \\
Nov & 623.3 & 17 \\
Dec & 90.2 & 10 \\
1991 Jan & 37.7 & 6 \\
Feb & 12.2 & 2 \\
\hline
\end{tabular}

Source : Biometry Division, CRI

The seed nuts used in the study were tall $x$ tall (CRIC 60) from the Ambakelle Seed Garden. A sample of 125 selected seed nuts were used in five different treatments. Treatments consisted of five different potting media as described in Table 2 . A sample of 25 seeds was used per treatment and were laid out in a completely randomized design.

The seed nuts were stored for two weeks in shade prior to planting to ensure that all seed nuts had reached the same stage of ripeness (Nuce de Lamothe and Wuidart, 1982). They were planted directly in polybags, filled with approximately 20 liters of potting mixture according to the treatment, with nuts positioned vertically. The nuts were dipped in Aldrin prior to planting as a measure of preventing termite attack. A light shade was maintained until about $75 \%$ germination was obtained in all treatments before they were exposed to full sunlight. The seedlings were watered once in three days when there was no rain. Weeding was done as and when weeds appeared 
on the surface. No pest or disease problems were encountered during the study.

The germination of nuts was observed for 30 weeks and the dates of germination were recorded for each nut. A seed nut was considered to have germinated when the plumule emerged out of the husk (Thomas, 1978). The other growth parameters such as girth (measured at the base of the plant), height of seedling (measured from the nut to the tip of the youngest fully-open leaf) and total number of leaves produced (Nuce de Lamothe and Wuidart, 1982) were recorded in all seedlings at 30 weeks from planting.

Table 2 The proportion of top soil, cow dung, coir dust and river sand in the five treatments

\begin{tabular}{|c|c|c|c|c|}
\hline \multirow[t]{2}{*}{ Potting Media } & \multicolumn{4}{|c|}{ Proportion of the constituents } \\
\hline & Top soil & Cow dung & Coir dust & River sand \\
\hline T1 & 3 & 2 & 1 & 0 \\
\hline $\mathrm{T} 2$ & 1 & 2 & 3 & 0 \\
\hline T3 & 0 & 2 & 1 & 3 \\
\hline $\mathrm{T} 4$ & 0 & 2 & 3 & 1 \\
\hline T5 & 0 & 0 & 0 & 6 \\
\hline
\end{tabular}

The statistical significance in gemination percentages in conventional mixtures and sand substituted mixtures at different times from planting were tested using the chi-square (contingency) analysis (Gomez and Gomez, 1976). The analysis of variance (ANOVA) procedure was followed to compare the difference in average days taken for germination, the initial growth of seedlings and the growth of seedlings of similar physiological age as determined from the age of germination (those germination on or before 20 weeks after seed planting) in the five treatments.

\section{RESULTS}

The temporal change in percentage germination of seed nuts in each treatment is shown in Table 3. At the very beginning ( 12 weeks after laying) the germination rate was significantly higher in T1 although the germination had commenced in all treatments except T4. At 16 weeks the rate was significantly higher in both $\mathrm{T} 1$ and $\mathrm{T} 2$ (conventional mixtures) as compared to sand substituted treatments T3, T4 and T5 $(\mathrm{P}<0.05)$. This trend continued up to 20 weeks from laying and disappeared subsequently achieving over $80 \%$ success in all treatments. By 28 weeks all treatments had reached over $88 \%$ germination.

Table 3 Temporal change in germination of tall $x$ tall (CRIC 60) seed coconuts in different potting media

Treatment Percentage germination of seed nuts at different times from planting

$12 \mathrm{Wk} \quad 16 \mathrm{Wk} \quad 20 \mathrm{Wk} \quad 24 \mathrm{Wk} \quad 28 \mathrm{Wk}$

\begin{tabular}{lrrrrr}
\hline T1 & 32 & 40 & 84 & 88 & 92 \\
T2 & 12 & 36 & 88 & 88 & 92 \\
T3 & 04 & 16 & 56 & 80 & 96 \\
T4 & 00 & 16 & 60 & 84 & 96 \\
Chi square value & $9.771^{*}$ & $6.731^{*}$ & $9.731^{*}$ & ns & ns \\
\hline
\end{tabular}

+ indicate chi square values for germinations and nongerminations at conventional mixtures (T1 and T2) and sand substituted treatments (T3 + T4 + T5).

* indicate the values significant at $\mathrm{P}<0.05$. ns, not significant 
The mean number of days taken for $88 \%$ germination (calculated from the date of germination of nuts) in each treatment are shown in Table 4. In T1 and T2 (conventional mixtures) the seed nuts took significantly less time to achieve the anticipated germination compared to T3, T4 and T5 (sand substituted mixtures). No significant differences were observed within groups of treatment, $\mathrm{T} 1$ and $\mathrm{T} 2$ (conventional) and T3, T4, and T5 (sand substituted).

Table 4 The mean number of days taken for $88 \%$ germination by tall $x$ tall (CRIC 60) seed coconuts in different potting media.

\begin{tabular}{ccr}
\hline Treatment & Average & Range \\
\hline T1 & 106 & $69-156$ \\
T2 & 112 & $61-1.43$ \\
T3 & 134 & $58-191$ \\
T4 & 138 & $103-191$ \\
T5 & 134 & $86-191$ \\
LSD $(P<0.05)$ & 16.13 & \\
Standard Error & 2.83 & \\
Coefficient of & & \\
Variation & 23.7 & \\
\hline
\end{tabular}

The growth parameters of the seedlings. i.e. girth, height and leaf number at 30 weeks from planting are shown in Table 5 . The girth at collar of the seedlings in $\mathrm{T} 1$ was significantly higher than T3 and T5. The percentage reduction in girth compared to T1 was highest in T5 (pure sand) and T3 (50\% sand mixed medium). The mean height of seedlings also showed a similar trend and here again the difference between $\mathrm{T} 1$ and $\mathrm{T} 4$ was not significant. The highest rate of leaf production was in $\mathrm{Tl}$ ( $50 \%$ top soil) showing a significantly faster rate than all other treatments. The rate in T2 was also significantly higher comared to T3, T4 and T5 (sand substituted media). The percentage reduction (taking T1 as control) was higest in T5 (pure sand). But unlike the growth parameters girth and height, the reduction in leaf number was lower in T3 (50\% sand mixture) than T4 (17.5\% sand mixture). However, the differences in the rate of leaf production between T3, T4 and T5 (sand substituted media) were not significant.

Table 5 Girth, height and leaf number of tall $x$ tall (CRIC 60) coconut seedlings after 30 weeks from planting in polybags containing different potting media

Treatment

Growth parameters assessed at 30 weeks

\begin{tabular}{llll} 
& $\begin{array}{l}\text { Mean Girth } \\
(\mathrm{cm})\end{array}$ & $\begin{array}{l}\text { Mean Height } \\
(\mathrm{cm})\end{array}$ & Leaf number \\
\hline T1 & 7.9 & & \\
T2 & $7.4(6.3)$ & 54.8 & 3.0 \\
T3 & $6.7(15.2)$ & $49.8(9.1)$ & $2.5(16.7)$ \\
T4 & $7.2(8.9)$ & $40.2(26.6)$ & $1.9(36.7)$ \\
T5 & $6.7(15.2)$ & $35.7(34.9)$ & $1.6(46.7)$ \\
LSD $(\mathrm{P}<0.05)$ & 0.9 & 9.6 & $1.5(50.0)$ \\
\hline
\end{tabular}

Value in parenthesis denotes percentage reduction in the growth measurement taking $\mathrm{Tl}$ as control 
Table 6 Girth, height and leaf number at 30 weeks from planting of tall $x$ tall

(CRIC 60 ) coconut seedlings germinated up to 20 weeks after laying

Treatment

Growth Parameters assessed at 30 weeks

\begin{tabular}{ccc}
$\begin{array}{c}\text { Mean Girth } \\
(\mathrm{cm})\end{array}$ & $\begin{array}{c}\text { Mean Height } \\
(\mathrm{cm})\end{array}$ & Leaf number \\
\hline
\end{tabular}

\begin{tabular}{clll} 
T1 & 7.95 & 55.8 & 3.1 \\
T2 & $7.43(6.5)$ & $50.4(9.7)$ & $2.5(19.4)$ \\
T3 & $7.29(8.3)$ & $46.2(17.2)$ & $2.3(25.8)$ \\
T4 & $7.53(5.3)$ & $54.8(1.8)$ & $1.9(38.7)$ \\
T5 & $7.09(10.8)$ & $41.1(26.3)$ & $1.8(41.9)$ \\
LSD $(\mathrm{P}<0.05)$ & 0.87 & 9.51 & 0.5 \\
\hline
\end{tabular}

Value in parenthesis denotes percentage reduction in the growth measurement taking $\mathrm{T} 1$ as control.

The growth parameters of seedlings which germinated up to 20 weeks from planting are given in Table 6. The girth showed no significant difference between treatments although a significant reduction in the height (taking $\mathrm{T} 1$ as control) was observed in $\mathrm{T} 5$. The leaf number in $\mathrm{T} 2$ was also significantly higher than those in sand substituted treatments except $\mathrm{T} 3$ ( $50 \%$ sand).

\section{DISCUSSION}

The germination of seed nuts at 24 weeks from laying was not affected by the substitution of top soil with river sand. However, the seedlings in river sand potting mixtures took significantly longer time to reach the desired levels of germination.

In the conventional nursery system with optimum management there should be over $80 \%$ germination in 20 weeks and the seed nuts that do not germinate by then are discarded as failures (Harries, 1983), In the polybag system (Wuidart, 1982) seed nuts are allowed to germinate in a prenursery bed and are then transplanted in polybgas, again up to 20 weeks or until $80 \%$ of seed nuts have germinated, whichever is fastest (Cano et al, 1989). In an experiment conducted parallel to the present study (Peries and Everard, 1991) seed nuts from the same lot as used in this study, achieved over $80 \%$ germination in conventional nursery beds at 20 weeks after laying. If seed nuts were transplanted into polybags from a pre-nursery the required $80 \%$ germination in 20 weeks would therefore, have been achieved.

The early germination and rapid growth of seedlings in polybags containing top soil compared to the sand substituted mixtures would be attributed partly to the high hydraulic conductivity of river sand. The increased percentage of macro pores in the sand substituted mixtures would have resulted in a more rapid rate of infiltratioin of water. The germination would have been delayed as a result of greater drying of the husk in sand substituted media through a greater build up of soil temperature. The long dry spell experienced during the germination period would have further enhanced the process of drying. In an early experiment where entry of water into husk was facilitated through partial slicing it promoted the rate of germination (Peries, 1984) which supports this argument. 
As a result of relatively early germination in the conventional mixtures, the seedlings would have slightly advanced in the their physiological age compared to those in the sand mixtures. When seedlings of similar physiological age were compared, it appeared that more vigorous seedling growth, in terms of height and leaf number was promoted in T1, where a high proportion top soil was contained in the mixture (50\%). Such vigorous growth was not seen in T2 where the proportion of top soil was less (16.5\%) although T2 showed a much better growth compared to sand substituted treatments; in particular T4 and T5. The decline in growth and vigour as a result of substitution of top soil with river sand could be attributed to the two characteristics of river sand, the poor nutritional status and its inability to hold water.

The problem of poor nutrition can be overcome by the addition of organic manure and inorganic nutrients to the potting media. The improved plant vigour in T3 and T4 compared to T5 (in terms of girth, height and leaf number) supports this argument where T3 and T4 both contained cow dung. In the conventional nursery, fertilizer application is not considered an essential practice where the seedlings are disposed of for planting after a 28 week nursery period (Anonymous, 1971). However, the positive influence of inorganic fertilizer (NP and K) on the vegetative growth of coconut seedlings has been observed by many workers (Child, 1974; Santiago, 1978; Almaden and Saniago, 1981). In the polybag system monthly application of an NPK fertilizer from the second month has been found to improve the girth of the seedling (Ho et. al., 1978). Wuidart and Nuce de Lamothe (1981) also practiced monthly application of fertilizer (N P K and Mg) in a polybag nursery. Thus it is evident that the addition of fertilizer to the sand substituted media could result in improved vigour of seedlings. A suitable fertilizer programme to derive the best benefit from sand mixtures in polybags is worthy of further investigation.

Besides nutrition the water holding capacity of the potting medium would also be a critical factor affecting seedling growth. The relatively improved seedling vigour in $\mathrm{T} 4$ and to some extent in T3 compared to pure sand (T5) where coir dust was a constituent in the potting media appears to be an indication of the importance of the ability of the medium to hold water thereby facilitating seedling germination and subsequent growth.

\section{CONCLUSION}

There was evidence that river sand will not adversely affect germination, when substituted for top soil in polybags. However, the rate of germination was slightly delayed and early seedling vigour was reduced in the sand substituted mixtures. It appeared possible to overcome these problems by increasing the nutritive status and the water holding capacity of the river sand. To derive the best benefits from the polybags system, a pre-nursery appears essential as the early germinating seedlings could then be identified and given the required after care. The use of a package of inputs to derive the best benefits from a polybag nursery system warrants further investigation.

\section{ACKNOWLEDGEMENTS}

We acknowledge the helpful suggestions and comments made by Mr. D T Mathes, Head, Biometry Division and Miss. M N Dias, Soil Scientist of the Coconut Research Institute, in the preparation of this paper. 


\section{REFERENCES}

Almaden, E.A. and Santiago, R.M. (1980). Response of coconut seedlings to spacing and application of Nitrogen and Potassium. Ann. Trop. Res. 2, 89-95.

Cano, S. B., Santos, G. A. and Bahala, R. T. (1989). Germination, growth and development of coconut seedlings in relation to seed nut preparation, position and polybagging (In press).

Child, R. (1974). Nutritional requirements and fertilizer practice in coconuts. Coconut 2 nd ed. Longman, London 130 - 156.

Anonymous (1971). Advisory leftlet No 2. Coconut Research Institute, Sri Lanka.

Gomez, K. A. and Gomez, A. A. (1976). Statistical procedures for agricultural research with emphasis on rice. I. R. R. I., Philippines.

Harries, H. C. (1983). A ten point coconut nursery programme to avoid germination problems. Planter, Kuala Lampur, 59, 207 - 214.

Ho, D. T., Loh, H. P. and Chan, E. (1978). Germination, nursery practices and field planting techniques for the MAWA hybrid coconut. Proceedings of the International Conference on Cocoa and Coconut.

Liyanage, D. V. and Abeywardene, V. (1957). Correlations between seed nut, seedling and adult palm characters in coconut. Tropical Agricuturist, CXIII, 325-340.

Liyanage, D. V. (1957). Report of the Botanist. Ceylon Coconut Q., 21, 22 - 24.

Liyanage, D. V. (1983). Improvement of coconut seed nut and seedling selection. Report No. 1 Consultant on Coconut Breeding, Coconut Development Authority.

Nuce de Lamothe M. de and Wuidart, W. (1982). Observation of vegetative development, flowering and yield characteristics of coconut. Oleagineux, 37, $291-300$.

Peries, R. R. A. (1984). Some observations on the pre-nursery system for raising coconut seedlings. Cocos $2,10-17$.

Peries, R. R. A. and Everard J. M. D. T. (1991). Ecological adaptation at the coconut nuresry? A preliminary investigation. Paper in preparation.

Santiago, R. M. (1978). Growth of coconut seedlings as influenced by different fertilizer levels and three soil types. Phill. J. Coco. Studies 3, 15 - 27.

Thomas, K. M. (1978). Influence of seed size and planting orientation on the germination and growth of coconut seedlings in the nursery. Indian J. Agric. Sci. 48, 63 - 67.

Wuidart, W. (1981). Production of coconut planting material - The polybag nursery Oleagineux, $367-373$.

Wuident, W. and Nuce de Lamothe, M. de (1981). Seed germination and development of coconut plants in function of nut position. Oleagineux, 36,600-603. 